\title{
ANALYSIS OF THE ERGONOMIC HAZARDS FOR THE CONSTRUCTION WORKERS IN AN EDUCATIONAL INSTITUTION
}

\author{
Manikandan $\mathbf{R}^{\mathbf{1}}$, Sathyanathan $\mathbf{M}^{\mathbf{2}}$ \\ ${ }^{1} P G$ Scholar, Knowledge Institute of Technology, Salem, India \\ ${ }^{2}$ Asst.professor, Department of Mechanical Engineering, Knowledge Institute of Technology, Salem, India
}

\begin{abstract}
This paper tells about the analysis of the ergonomic hazards for the construction workers in an educational institution. Construction work is one of the most hazardous works when compared to other work. Ergonomic hazards mostly occur for the construction workers. But they did not aware about the ergonomic hazards, so they involuntarily take the risk. The solution for the ergonomic hazards is only to creating awareness to the construction workers, and provides proper training to work in a safe way [1]. The management takes the responsibility for creating awareness to the construction workers to eliminate the ergonomic hazards and to improve the efficiency of the workers.
\end{abstract}

Keywords: Construction, ergonomic hazards, awareness, workers. $* * *_{-}$

\section{INTRODUCTION}

The construction is defined as the building of something, typically a large structure. Ergonomics is the science relating to the efficient use of human energy in the work place. Ergonomics includes design of work environment, tools and equipment. In a present trend compare to other occupational disease ergonomically related disease have higher impact.

The nature of work itself imposes a lot of ergonomical hazards to the construction workers. Because they normally work in awkward position and due to the work pressure they lift heavy loads in the stairways this will stress in back and create back injury. Normally ergonomic related problems are not quickly occurs to the workers they starts to react only over a long period of exposure but they are very dangerous problems.

So in this study an analysis is carried out in order to finding out the ergonomic risks that are present in an educational institution.

\section{CONSTRUCTION WORKS}

There are about ninety people involving in different construction works on contract basis. A few more people are also involved in the construction work on daily payment basis. They work eight hours a day. The following are the construction works involved in the educational institution.

\subsection{Excavation Work}

The major hazard in the excavation work is the whole body vibration because they use earth movers for the excavation work. There are two machine operators who involved in the excavation work exposed to ergonomic problems like disc injuries due to poor seat and cab design. One worker operates the hand driller resulting in trigger finger due to hand arm vibration.

\subsection{Masonry Work}

There are ten members involved in the masonry work. They manually carry the masonry blocks from the ground level to the high level floors so they exposed to WMSD'S such as tension neck syndrome due to unsafe lifting techniques and over load. Because they are uneducated so they do not know how much amount of the load is the safe limit.

\subsection{Concrete Formwork}

There are ten members involved in the concrete form work. This work is almost manually done by the workers, they does not use machines this will create a lot of ergonomical problems to the workers. But there is no other way for doing the concrete formwork, so it is one of the toughest work in construction work.

\subsection{Structural Steel Work}

There are seven members involved in the structural steel work. The workers bend the steel rods manually by giving their entire body force. So they get tired quickly by continuing this type of work for a long time they meet severe back pains, because when they bend the spinal cord bones get compressed this leads to damage of the disc which provides cushion effect and prevent the bone joints from touching.

\subsection{Concrete Floor}

There are thirteen members involved in the concrete floor work. In this work the concrete floor is laid by the workers in order to maintain the equal surface level of the floor they normally work in a awkward postures for a long time, sometimes the whole day. Incase if they not concentrate well in this work then the floor surface will not in equal 
level then the whole work will get wasted this leads to material loss and time loss. Normally work rotation method is employed to minimize the ergonomical problems.

\subsection{Plumbing}

There are four workers involved in the plumbing work. Normally plumbing works are done side by side to the concrete floor work. So this work involves lot of works above the shoulder height. The workers get fatigue quickly for this type of overhead works they lost their control and balance. So this type of work is carried out only by shit basis.

\subsection{Electrical Work}

There are two certified electricians for the electrical work in that construction site. They install the electrical lines for the constructing building. For this purpose they use some hand tools which are not standard tools for the electrical work this will generate a lot of ergonomical problems after a long period of usage.

\subsection{Roofing}

One of the important and toughest works in the construction work is roofing work. There are ten workers involved in the roofing. While roofing the workers should carefully handle the materials otherwise it results in back pain.

\subsection{Building Exteriors}

The most time consuming work in the construction work is building the exteriors. For this work twenty workers are involved. The building comprises of three floors in which they install about fifty five windows, this present the risk of lifting the windows and fixing it in the space provided by standing on the scaffold. And also for outer finishing of the building they work in the awkward postures.

\subsection{Scaffold}

For scaffold work six workers are involved. Scaffold erection is the very first work in order to work in the height, but the scaffold is not a permanent structure so they simply install the scaffold. In order to install the scaffold the lift the steel bars by providing a large amount of force this will stress in the back.

\subsection{Painting}

There are five workers involved in the painting work. Painting workers manually carry the paint to the heights this will create the pain in the hands. And also they normally work in the abnormal positions, and the painting activity itself involves continual brushing of the paint to the building this will create thoracic outlet syndrome to them.

\subsection{Flooring Installation}

There are seven workers involved in the flooring installation. The final work in the construction of the building is the flooring installation. The workers mostly kneel down to the floor for this work this will leads to the knee injuries and back pain problems.

\subsection{Materials Handling}

There are six workers involved in the materials handling. Material handling means transporting the bricks and the mixture of the sand and the cement to the place where they need. They normally carried this materials on the head this will stress the neck leads to tension neck syndrome.

\section{ERGONOMIC DISEASE IN CONSTRUCTION}

The most prevalent disease that normally occurs to the construction workers is work related MUSCULOSKELETAL DISORDERS. It is an impairment of bodily structure.

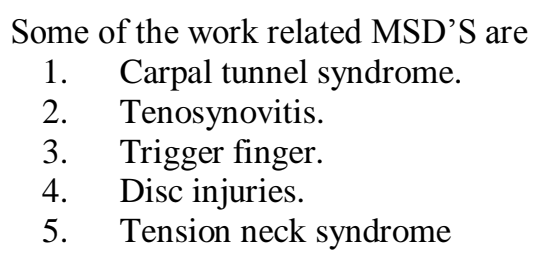

\subsection{Carpal Tunnel Syndrome}

It is a type of nerve entrapment results from the buildup of pressure on the median nerve for the construction workers due to carrying of loads and strong gripping for long time.

\subsection{Tenosynovitis}

Tenosynovitis is the inflammation of tendons and sheath associated with tasks demanding extreme wrist deviation of the construction workers.

\subsection{Trigger Finger}

It is one type of tenosynovitis arises due to flexing of finger frequently against resistance.

\subsection{Disc Injuries}

Disc injury is the damage that occurs to the disc on the spinal card due to frequent bending of back.

\section{SOLUTIONS TO MITIGATE THE WMSD'S}
1. Engineering control.
2. Administrative control.
3. Proper usage of personal protective equipment's.
4. Creating awareness about ergonomic diseases.
5. Provide training about safe lifting techniques.
6. Provide training about ergonomic principles.

\subsection{Engineering Controls}

1. Use mechanical equipment's to lift the period of time spend in one position and ensure heavy objects.

2. Reduce the weight of a load to limit force exertion. 


\subsection{Administrative Control}

1. Require that heavy loads are only lifted by two people to limit force exertion.

2. Provide periodic breaks.

3. Design a job rotation system.

\subsection{Personal Protective Equipment's}

1. Use helmet to protect from fall of objects from height.

2. Wear good gloves to avoid injuries due to sharp edges.

\subsection{Safe Lifting Techniques}

1. Think before lifting/handling.

2. Adopt a stable position.

3. Don't flex the back any further while lifting.

4. Keep the load close to the waist.

5. Start in a good posture.

6. Avoid twisting the back or learning sideways.

7. Keep the head up when handling.

8. Move smoothly.

9. Don't lift or handle more than can be easily managed.

10. Put down, and then adjust.

\subsection{Ergonomic Principles}

According to [2], application of ergonomics principles to the design of man machine interfaces, including displays of plant and process information, control devices and panel layout need to be considered seriously in designing the best ergonomic design for the workers. On the other hand [3] stated that, "conservative" treatment of these disorders, especially in the early symptomatic stages, using workplace evaluation for risk factors followed by modifications and rest to reduce inciting or aggravating positions and or movements. While [4] claims that, the goals of intervention are to reduce awkward positions, minimize the need to use excess force, reduce highly repetitive movement, reduce the sufficient rest/recovery period. It was hypothesized by [5] that compared to workers who received an ergonomic evaluation and tailored modifications of existing workstation, symptomatic workers who received both the ergonomic and job stress management intervention would have greater improvement in outcomes.

1. Alternate postures as well as movements.

2. Avoid excessive reaches.

3. Avoid carrying out tasks above shoulder level.

4. Limit the weight of the load that is lifted.

5. Use mechanical aids.

6. Avoid carrying load with one hand.

\section{CONCLUSION}

The ergonomic problems for the construction worker in an educational institution are analyzed and the solutions for the problem are also discussed in this study. The administration also takes the responsibility to control the ergonomic hazards by provide proper training and education because the workers have not much knowledge about ergonomics. The management not only concentrates in the work, they also concentrate in health of the workers. If the health of the workers is improved then the efficiency of the workers is also improved.

\section{REFERENCES}

[1] Tayyari F And Smith J.L (1997). Occupational Ergonomics Principle And Applications. Chapman \& Hall (London)Te H.P, \& Kleiner B.H (2001). New Development Concerning The Occupational Safety And Health Act Volume 43 Number 1/2 2001.

[2] Dias L.M.A \& Coble R.J, (1996). Implementation of Safety and Health on Construction Sites.Proceeding of the First International Conference of $C I B$ Working Commission W99. Lisbon, 203-317.

[3] Michael F., Rena A.N,Grant D.H, Lennart D., Danielle A., Heather R., (2004). Applied Ergonomics. Elseveir, 565-574.

[4] Piligan G.,Herbert, R. , Hearns,M.,Dropkin,J., Landsbergis,P., Cherniack,M.(2000 ).Evaluation And Management Of Chronic Work Related Musculoskeletal Disorders Of The Distal Upper Extremity. American Journal Of Industrial Medicine 37, 75-93.

[5] Bryne.K. (2002). Ergoclinic Corpmed.Roebling, New Jersey. 